\title{
The Development of Afferent Projections to the Robust Archistriatal Nucleus in Male Zebra Finches: A Quantitative Electron Microscopic Study
}

\author{
Kathrin Herrmann and Arthur P. Arnold \\ Department of Psychology and Laboratory of Neuroendocrinology of the Brain Research Institute, University of California, \\ Los Angeles, California 90024-1563
}

\begin{abstract}
Because the projections into the robust nucleus of the archistriatum (RA) are thought to play important roles in song learning and sexual differentiation of the zebra finch (Poephlla guttata), quantitative electron microscopic techniques were used to measure the development of synaptic input to the neuropil of RA in this species. Two nuclei [hyperstriatum ventrale pars caudalis (HVC) and lateral magnocellular nucleus of the anterior neostriatum (IMAN)] that send projections to RA were lesioned at each of three different ages: $25 \mathrm{~d}$ after hatching, $\mathbf{5 3} \mathrm{d}$, and adulthood. In tissue from RA processed for conventional electron microscopy, lesion-inducied degeneration was used to identify synapses from either HVC or IMAN. Axosomatic synapses were excluded from analysis. In control (unlesioned) animals, the density of synapses in neuropil increased slightly between days 28 and 56 and remained constant thereafter. Because of a large increase in the volume of RA, the total number of synapses in neuropil of RA tripled between days 28 and 56 and decreased significantly between day 56 and adulthood. The density and total number of synapses in neuropil originating from $\mathrm{HVc}$ increased significantly between days 25 and 53 , but did not change significantly thereafter. In contrast, the density and total number of synapses from IMAN decreased significantly between days 25 and 53 and did not change thereafter. Presynaptic terminals from IMAN were larger than those from HVC. These data demonstrate that the most rapid phase of song learning is accompanied by a major rearrangement of synaptic contacts into RA that stem from HVc and IMAN.
\end{abstract}

Male passerine birds learn songs from other members of their species, often during critical periods early in development. Because learning is normally confined to a limited period in these species, it is possible to examine brain regions that control song to determine how these regions change during the period of learning. The neural changes correlated with learning represent candidates for the neural basis of learned changes in song.

In zebra finches, males learn songs from their fathers during

\footnotetext{
Received Aug. 13,1990; revised Jan. 10, 1991; accepted Feb. 6, 1991.

We thank Beau Mitchell for talented technical assistance, Melissa Jackson for editorial help, and Drs. Barney Schlinger and J. Arthur Woodward for assistance with statistical analysis. This research was supported by Deutsche Forschungsgemeinschaft Grant He1539/1-1 and NIH Grant DC00217.

Correspondence should be addressed to Dr. Kathrin Herrmann, Department of Neurobiology, Stanford University School of Medicine, Stanford, CA 94305. Copyright (c) 1991 Society for Neuroscience 0270-6474/91/112063-12\$03.00/0
}

the first three months after hatching (Immelmann, 1969; Böhner, 1983). At first, zebra finches begin the sensory phase of song development, in which they memorize the acoustic features of the father's song. The timing of this phase has been determined in experiments in which males were acoustically isolated at various ages, or were switched from one acoustic environment to another. The sensory phase probably begins after about day 20 (Arnold, 1975), and usually ends by about day 35, at least in birds housed in large aviaries similar to those used in the present experiments (Böhner, 1987). Under some conditions, sensory acquisition lasts longer but is mostly complete by day 50 (Eales, 1985, 1987). The second phase of learning, called sensory-motor learning, involves learning to coordinate the motor apparatus to produce good copies of the model sounds learned earlier. The onset of singing, which marks the onset of sensorymotor learning, occurs around 25-30 d after hatching. All of the adult elements are typically in place by around $60 \mathrm{~d}$, after which only minor changes occur until fully adult songs are produced at around $90 \mathrm{~d}$ (Arnold, 1975). Thus, the period between 25 and $60 \mathrm{~d}$ of age encompasses most of the two phases of song learning.

There are dramatic changes occurring during this period in the neural regions controlling song. The robust nucleus of the archistriatum (RA), which projects to the motoneurons (nXIIts) of the vocal organ, the syrinx, increases in volume as the result of an increase in the size of RA neurons and an increase in the amount of neuropil in RA (Bottjer et al., 1985, 1986; Konishi and Akutagawa, 1985; Herrmann and Bischof, 1986). Two nuclei that send projections to RA (Bottjer et al., 1989) also undergo extensive changes. The nucleus originally named hyperstriatum ventrale, pars caudalis ( $\mathrm{HVc}$ ) undergoes an increase in the number of neurons as the result of addition of neurons generated after day 20 (Bottjer et al., 1986; Nordeen et al., 1987; E. Nordeen and K. Nordeen, 1988; K. Nordeen and E. Nordeen, 1988). Many of these new HVc neurons project to RA, as evidenced by retrograde labeling experiments. Indeed, anterograde tract tracing experiments indicate that the axons of $\mathrm{HVc}$ fail to innervate RA up through day 25 , but do enter RA after day 35 , suggesting that there is a rapid growth of HVc axons into RA around day 30 (Konishi and Akutagawa, 1985). These observations lead to the hypothesis that the growth of the HVc-toRA pathway is essential for the process of song learning. Similar changes in this pathway also occur in other species correlated with different forms of song learning (Arnold, 1991).

At the same time, there are profound changes in a second nucleus that projects to RA, the lateral magnocellular nucleus 
of the anterior neostriatum (lMAN). This nucleus decreases in volume and loses half of its neurons between days 25 and 53, probably because of cell death (Bottjer et al., 1985; Bottjer and Sengelaub, 1989). Lesions of $1 \mathrm{MAN}$ are ineffective in disrupting song in adult zebra finches, but they prevent song learning if the lesions are made before day 65 (Bottjer et al., 1984). Thus, IMAN may play a special role during the period of song learning.

These various studies draw attention to RA and its two afferent nuclei, HVc and IMAN, as possible sites of neural changes responsible for learning. The present article examines the changes that occur in synaptic input to RA during the period of learning. We address several questions raised by previous studies. For example, we have measured the developmental changes in the number of synapses onto RA neuropil that originate from $\mathrm{HVc}$, because the growth of the HVc-to-RA pathway implies that there is a developmental increase in the number of such synapses. It has also been suggested that the simultaneous loss of IMAN neurons and increase in HVc neurons may be causally related. Perhaps the ingrowing axons from HVc displace IMAN synapses and contribute to the death of IMAN neurons. Thus, we have examined quantitatively the relationship between changes in RA synapses of HVc origin and of IMAN origin to evaluate this hypothesis more critically.

Using lesion-induced electron-dense degeneration (Blackstad, 1965; Matsumoto and Arai, 1981; Ichikawa et al., 1985; Moriiumi et al., 1987; Canady et al., 1988) to describe the development of projections from HVc and IMAN in the neuropil of RA, we counted the density and number of synapses at $25 \mathrm{~d}$ of age (when males are beginning the sensory phase, and when lesions of IMAN disrupt song development), at $53 \mathrm{~d}$ of age (towards the end of sensory-motor learning, when IMAN lesions are less effective), and in adult birds (after song crystallization). The data show that song learning is accompanied by a major increase in the synaptic connections from $\mathrm{HVc}$ and a drastic decrease in the number of synapses from IMAN. The most dramatic changes occur between days 25 and 53 , when most song learning occurs.

\section{Materials and Methods}

\section{Animals and surgery}

We used 53 male zebra finches (Poephila guttata) from our breeding colony, aged $25 \mathrm{~d}, 53 \mathrm{~d}$, or $>100 \mathrm{~d}$ (adult). The animals were deeply anesthetized with $0.05 \mathrm{ml}$ Equithesin. Stereotaxic lesions of either $\mathrm{HVc}$ $(25 \mathrm{~d}, n=7 ; 53 \mathrm{~d}, n=7$; adult, $n=6$ ) or IMAN ( $25 \mathrm{~d}, n=7 ; 53 \mathrm{~d}, n$ $=8$; adult, $n=6$ ) were made by a unilateral injection of $0.5-1 \mu$ l ibotenic acid ( $10 \mu \mathrm{g}$ dissolved in $3 \mu \mathrm{l}$ of $0.1 \mathrm{M}$ phosphate buffer) with the aid of a 2- $\mu$ l Hamilton syringe (Schwarcz et al., 1979). The stereotaxic coordinates for HVc (relative to the "Y" junction of the two caudal cerebral sinuses at the top to the brain) were AP, $0 ; \mathrm{L}, 2.0-2.4$; depth, 0.6. For IMAN lesions, we injected ibotenic acid at A, 3.8-4.0; L, 1.6-1.8; depth, 2.0-3.0.

Because neurogenesis and cell death are naturally occurring events in juvenile and adolescent zebra finches (Kirn and De Voogd, 1989), we also measured intact, unlesioned zebra finches of the same ages $(28 \mathrm{~d}$, $n=3$; $56 \mathrm{~d}, n=4$; adults, $n=4$; at the same ages the lesioned birds were killed; see below) as controls to determine the frequency of naturally occurring degenerating synapses.

\section{Survival time}

To recognize synaptic terminals from either HVc or IMAN in the neuropil of RA, we lesioned either HVc or IMAN to produce degenerating synaptic profiles containing an electron-dense axoplasmic matrix. Following a lesion, the early stages of degeneration involve a slight darkness of the terminal and swollen mitochondria and synaptic vesicles. After a longer survival time, changes include an increased electron density (darkness), often with the collapse of the presynaptic profile. Following longer survival times, microglia and astrocytic processes invade the area, resulting in a detachment of pre- and postsynaptic elements and the engulfing and final phagocytosis of the presynaptic element (Mugnani and Friederich, 1982). For each type of lesion, we determined empirically the survival time at which the degenerating synaptic profiles were easily recognizable by their dark appearance, but nevertheless maintained contact with the postsynaptic membrane. In this manner, we could classify synapses according to the type of postsynaptic contact, either dendritic shaft or spine. We found that in zebra finches with an $\mathrm{HVc}$ lesion, regardless of age, rather light degenerating profiles could be seen as early as $2 \mathrm{~d}$ after the lesion, but they were still difficult to identify at this stage. At $60 \mathrm{hr}$ following the lesion, dark, electron-dense synapses could be easily identified. A survival time of $120 \mathrm{hr}$ resulted in a high number of degenerating profiles engulfed by microglia, but few degenerating presynaptic terminals were still attached to the postsynaptic membrane. We chose $60-96 \mathrm{hr}$ as the optimal survival time for recognizing degenerating synapses from $\mathrm{HVc}$, because within this period there was no apparent change in the ability to recognize terminals.

The optimal survival time for mapping degenerating synapses from IMAN in RA was significantly longer. At $60 \mathrm{hr}$ or more than $120 \mathrm{hr}$ after the lesion, few degenerating synapses could be identified, whereas a large number of electron-dense terminals were found after a survival of 84-120 hr. Therefore, a postlesion time of 90-120 hr was used to rccognize synapses from IMAN occurring in RA. Similar optimal survival times have also been found after electrolytic lesions in the canary (Canady et al., 1988).

\section{Tissue preparation}

After the survival times described above, the birds were deeply ancsthetized with $0.08 \mathrm{ml}$ Equithesin and perfused transcardially with $0.75 \%$ $\mathrm{NaCl}$, followed by a cold $\left(4^{\circ} \mathrm{C}\right)$ solution containing $4 \%$ paraformaldehyde and $1 \%$ glutaraldehyde in $0.1 \mathrm{~m}$ phosphate buffer $(\mathrm{pH}, 7.2)$. After a period of at least $2 \mathrm{hr}$, the brains were dissected out and stored in the same fixative overnight at $4^{\circ} \mathrm{C}$. On the following day, sagittal sections of the hemisphere ipsilateral to the lesion were cut with a vibratome at a thickness of $50 \mu \mathrm{m}$ and collected in phosphate buffer. Tissue pieces containing RA were dissected out with a blade and rinsed in phosphate buffer. These pieces were postfixed in $1 \%$ osmium tetroxide, stained en block with aqueous uranyl acetate, dehydrated in a graded series of ethyl alcohols, emersed in propylene oxide, and embedded flat in Epon 812. Semithin sections were cut with an LKB ultramicrotome and stained with toluidine blue to identify the position of RA within the section. Ultrathin sections (silver) were cut with a glass knife, mounted onto 300 -mesh grids, counterstained with lead citrate, and observed in the electron microscope.

\section{Data collection}

For the quantitative investigation of the number of degenerating and nondegenerating synapses in RA, micrographs intended for counting were randomly selected throughout neuropil within the center of this nucleus, carefully excluding the borders of RA. From each animal, 20 40 micrographs were taken at a nominal magnification of $7000 \times$ (total area of each micrograph, $93.5 \mu \mathrm{m}^{2}$ ), which after photographic enlargement yielded a magnification of $21,000 \times$. The micrographs were coded and scored by a person who was unaware of the treatment condition of the animal. To maximize our neuropil sample, the sampling excluded areas containing mostly non-neuropil elements: neural and glial somata, blood vessels, and large myelinated axons. This procedure allowed us to avoid numerous micrographs of RA that were devoid of synapses. Indeed, axosomatic synapses were relatively rare, and we never observed a degenerating axosomatic synapse in any of our material. Thus, our data on synapses in neuropil undoubtedly represent a picture of the majority of synapses in RA.

Normal, nondegenerating synapses were identified on the basis of three features: a postsynaptic membrane density (PSD), a clearly visible synaptic cleft separating pre- and postsynaptic elements, and synaptic vesicles adjacent to the presynaptic membrane. Degenerating synaptic profiles were identified on the basis of an electron-dense presynaptic terminal, a synaptic cleft, and a PSD.

\section{Data analysis}

Synapse density. To measure the number of synaptic contacts per unit area $\left(100 \mu \mathrm{m}^{2}\right)$, each synapse was marked on the photomicrograph. Each synaptic profile was classified as degenerating or nondegenerating, and 
according to the nature of the postsynaptic element: dendritic shaft, dendritic spine, growth cone, or soma. Because our sample was exclusively taken from the RA neuropil, the incidence of somatic synapses was less that $0.5 \%$ in all groups. Axon terminals that made synaptic contacts with two different postsynaptic membranes were counted as two synapses. In addition, the incidence of synapses with perforated PSDs was recorded.

Length of the PSD. The length of the PSD was measured with the aid of a digitizing tablet attached to a microcomputer. In each brain, the mean length of PSDs was calculated from 100-120 PSDs whose entire length was contained within the micrograph frame. In all lesioned brains, the PSD length was calculated separately for degenerating and nondegenerating synaptic profiles. There was never a statistically significant difference in size between degenerating and nondegenerating synapses from any brain. The PSD lengths were further used to calculate synapse numbers (see below). For these calculations, the value for PSD size was taken as the mean of nondegenerating PSDs, because the incidence of degenerating PSDs was so low in some brains that estimates of degenerating PSD size were variable and inaccurate.

Total number of synapses. To calculate the total number of synaptic contacts in the neuropil of RA, we used the stereological formula of DeHoff and Rhines (1961): $N_{v}=N_{a} / d$, where $N_{v}$ represents the number of synapses per unit volume, $N_{a}$ is the mean number of synapses per unit area, and $d$ is the mean length of profiles of synapses (PSDs). This formula gives accurate and consistent results on truly representative samples (Colonier and Beaulieu, 1985). $N_{v}$ was then multiplied by an estimate of the volume of neuropil ( $\left.V_{\mathrm{np}}\right)$ in RA to calculate the total number of synapses in the neuropil. $V_{n p}$ was estimated at each age in $50-\mu \mathrm{m}$ vibratome sections from untreated birds $(n=4$ for each age) that were prepared using procedures identical to those used in preparing the tissue for electron microscopic analysis.

To measure $V_{n \mathrm{n}}$, we first estimated the total volume of RA by measuring the area occupied by RA in consecutive sections, summing these values and multiplying by the sampling interval $(50 \mu \mathrm{m})$. The total volume of RA was then multiplied by the proportion of RA occupied by neuropil, which was estimated as follows. In the brains prepared for measurement of RA volume, small fields of RA were viewed in the light microscope with a $100 \times$ objective. Use of a high-power objective meant that there was a small depth of field, so that only a thin "section" (several microns thick) was in focus at any one time. Within this thin section of focus, the cross-sectional areas of all cell bodies were measured using a digitizing tablet and microcomputer-based morphometrics program. Each field of view was at least $1049 \mu \mathrm{m}^{2}$, and at least 40 such fields were measured in RA in each of the 12 Nissl-stained control brains. The percentage of volume occupied by neuropil was taken as 100 minus the percentage of volume occupied by cell bodies, which was calculated as the sum of cell body areas divided by the area of the sampling field, multiplied by 100 . The percentage occupied by cell bodies was $37.1 \pm$ $0.8 \%$ (mean + SFM) for the $28-\mathrm{d}$ group, $18.2 \pm 2.9 \%$ for the $56-\mathrm{d}$ group, and $18.4 \pm 2.5$ for the adult group. The value of $V_{\mathrm{np}}$ was taken as a constant for all animals in each age group.

Size of degenerating synaptic profiles. In all lesioned animals, the area of all degenerating synaptic terminal profiles was measured on a graphics tablet so that mean values of synapses originating from IMAN and $\mathrm{HVc}$ could be compared. Terminals that were cut longitudinally, and hence had an elongated shape (including a portion of the axon), were excluded from these measurements.

\section{Size of the lesion}

The size of the lesion was confirmed by mounting the remaining portion of the vibratome sections (from which the piece containing RA had been dissected) onto gelatin-coated slides. The sections were stained with thionin, and the lesion was inspected under the light microscope. Because both HVc and IMAN have clearly defined boundaries, it was easy to determine whether these areas were completely damaged (i.e., where the Nissl-stained tissue was devoid of neuronal somata). Birds with incomplete lesions were discarded from the study. In the case of $\mathrm{HVc}$ lesions, birds were also discarded if the lesion encroached in any way on the adjacent neostriatal tissue. Because the projection from IMAN to RA passes just ventral and lateral to HVc (Bottjer et al., 1989), these animals were not analyzed because the degencrating synapses in RA might otherwise have included a mixture originating from both HVc and IMAN. The use of ibotenic acid also helped to prevent damage to IMAN fibers, because this toxin is thought to leave axons en passage intact (Schwarcz et al., 1979). In birds that received lesions of IMAN, the lesions sometimes included adjacent neostriatal tissue, but in no case did the lesion include any portion of area $X$.

\section{Statistical analysis}

To analyze differences between the three age groups of unlesioned control birds, a one-way analysis of variance (ANOVA) was performed for each parameter measured, with $n=$ number of animals in each group. If there was a significant main effect of age, post hoc tests (one-way ANOVA and Duncan's multiple-range test) were also run to determine which individual groups differed from each other.

To analyze differences among lesioned groups of birds, we used a $3 \times$ 3 two-way ANOVA for each parameter with main factors of age (three levels) and type of lesion (three levels: HVc lesion, IMAN lesion, and no lesion). In each of the two-way ANOVAs, the data were transformed with a square root or logarithmic transformation so that the data met the assumption of equality of variances, as assessed by a likelihoodratio test (Woodward et al., 1990). In the case of ANOVAs comparing density or number of synapses on spines, these algebraic transformations did not result in groups with equal variances. In these two cases, we omitted the unlesioned control animals from the analysis and ran the two-way ANOVA with only two levels (IMAN and HVc lesion) of the treatment factor. This procedure allowed us to compare the spine synapses in IMAN- and HVc-lesioncd birds using data that met the assumptions for these parametric tests. In all of the two-way ANOVAs, if there was a main effect of age or treatment, or an interaction, planned comparisons were computed to determine which of the individual groups differed significantly from each other. A $p$ value less than 0.05 was taken as significant.

\section{Results}

\section{Normal development of $R A$ : control birds}

Volume. The volume of RA increased more than twofold between days 28 and $56(p<0.05$; from $0.112 \pm 0.014$ to 0.263 $\pm 0.015 \mathrm{~mm}^{3}$ ), confirming previous reports (Bottjer et al., 1985; Konishi and Akutagawa, 1985; Herrmann and Bischof, 1986). After day 56, RA volume decreased by about $15 \%$ to an adult value of $0.223 \pm 0.02 \mathrm{~mm}^{3}$. The volume of neuropil in RA was $0.079 \pm 0.009 \mathrm{~mm}^{3}$ at $28 \mathrm{~d}, 0.215 \pm 0.012 \mathrm{~mm}^{3}$ at $56 \mathrm{~d}$, and $0.182 \pm 0.017 \mathrm{~mm}^{3}$ in adults.

Synapse density. This parameter did not change significantly between day 28 and adulthood (Fig. 1). However, there was a significant rearrangement between synapses on dendritic shafts and spines during that time. The density of synapses on dendritic shafts increased steadily with age $[F(2,8)=5.12 ; p<0.037]$. The density of synapses on dendritic spines also changed significantly with age $[F(2,8)=8.56 ; p<0.01]$, though the developmental trend was different. The density of synapses on spines increased significantly between days 28 and 56, and then declined significantly $[F(1,6)=8.56 ; p<0.011)$ by adulthood. At $28 \mathrm{~d}, 0.16 \pm 0.21$ synapses per $100 \mu \mathrm{m}^{2}$ made synaptic contacts with growth cones. In 53-d as well as in adult zebra finches, no synapses on growth cones were identified. Because we avoided somata during sampling, the incidence of somatic synapses was low at all age groups $\left(0.01-0.02 / 100 \mu \mathrm{m}^{2}\right)$.

Length of PSDs. In control birds, the length of the synaptic apposition zone increased significantly with age $[F(2,8)=8.91$; $p<0.009$ ]. A significant growth occurred between days 28 and 56 (from $0.257 \pm 0.006$ to $0.296 \pm 0.005 \mu \mathrm{m}$ ), after which there was no significant change into adulthood $(0.278 \pm 0.008)$. This pattern of results found in controls was confirmed when data from both control and lesioned birds were pooled.

Total number of synapses. The total number of synapses in neuropil of RA changed significantly with age [Fig. $2 ; F(2,8)=$ $88.4 ; p<0.0001]$. The total number of synapses tripled between days 28 and $56(p<0.0001)$, after which the number decrcased significantly by about $16 \%(p<0.023)$. 


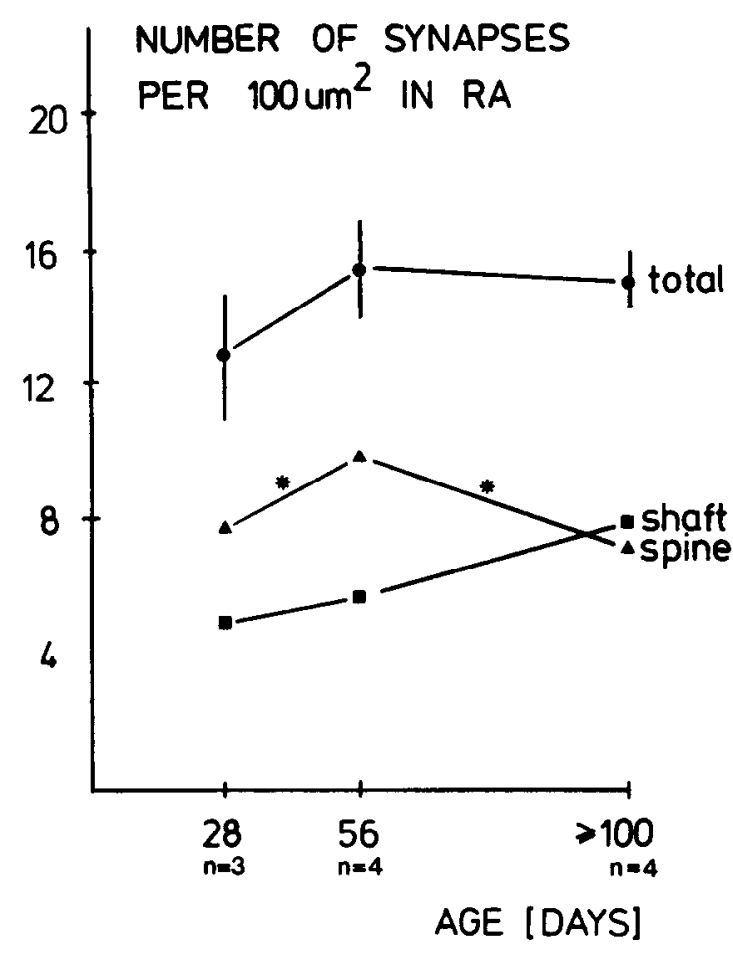

Figure 1. Postnatal changes in the density of synapses in RA of control animals (mean $\pm S E M$ ). The number of synaptic contacts per unit area $\left(100 \mu \mathrm{m}^{2}\right)$ did not change with age, though this parameter increased slightly between days 28 and 56 . However, there was a significant rearrangement of synapses on dendritic spines and shafts. The density of synapses on dendritic shafts increased significantly between day 28 and adulthood, whereas synapses that made contact with dendritic spines increased significantly between days 28 and 56 and then decreased by adulthood. ${ }^{*}, p<0.05$.

Density and number of degenerating synapses. The density of synapses degenerating from natural causes was low and constant across age in the control birds (see Fig. 5). The density of degenerating profiles on dendritic shafts did not change with age, nor did the density on dendritic spines. Similarly, the total number of degenerating synapses in neuropil of RA did not change with age $\left[25 \mathrm{~d}, 0.41 \pm 0.65 \times 10^{6}\left(0.19 \times 10^{6}\right.\right.$ on shafts, 0.22 $\times 10^{6}$ on spines); $53 \mathrm{~d}, 0.95 \pm 0.9 \times 10^{6}\left(0.36 \times 10^{6}\right.$ on shafts, $0.59 \times 10^{6}$ on spines); adult, $0.56 \pm 0.82 \times 10^{6}\left(0.39 \times 10^{6}\right.$ on shafts, $0.17 \times 10^{6}$ on spines)]. Because of the constancy and low incidence of degenerating synapses, we did not correct the values for lesion-induced degeneration (discussed below) by subtracting the small amount of naturally occurring degeneration.

Number of synapses with perforated PSDs. The density and total number of synapses with perforated postsynaptic densities did not change significantly with age. However, in control zebra finches the density of perforated PSDs was higher on dendritic shafts than on dendritic spines at all ages $(25 \mathrm{~d}, 0.38 \pm 0.14$ vs $0.27 \pm 0.12 ; 53 \mathrm{~d}, 0.38 \pm 0.24$ vs $0.24 \pm 0.13$; adult, $0.75 \pm$

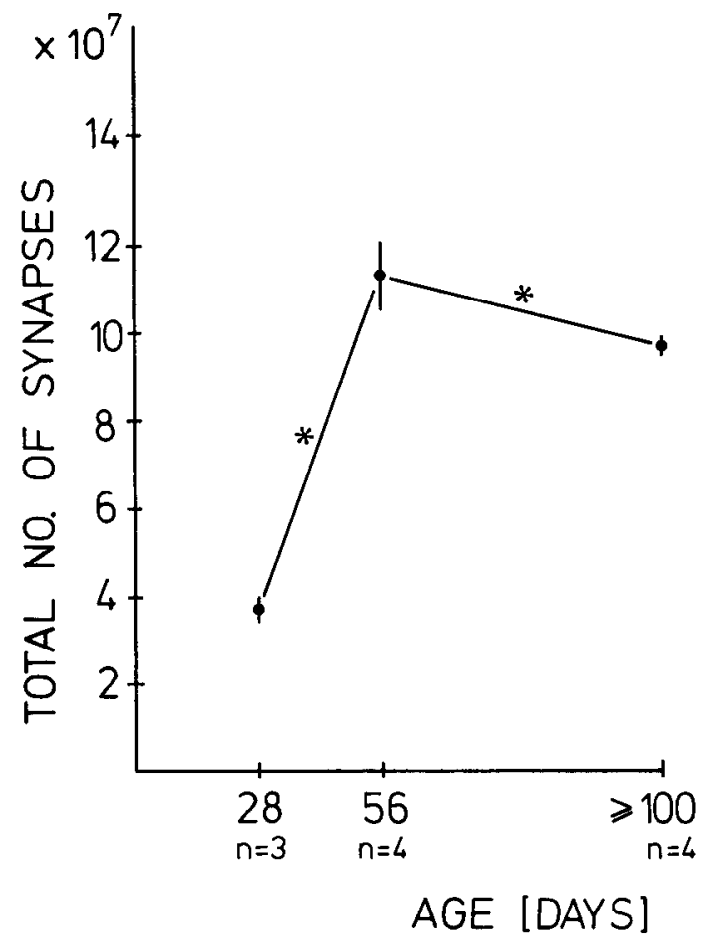

Figure 2. Postnatal changes in the total number of synapses in neuropil of RA (mean \pm SEM), as calculated via the formula by DeHoff and Rhines (1961). Because of the large volume increase in RA neuropil, the total number of synapses tripled between days 28 and 56 and decreased by about $16 \%$ between day 56 and adulthood. Both the increase and the decrease were statistically significant. ${ }^{*}, p<0.05$.

0.20 vs. $0.13 \pm 0.10$ per $100 \mu \mathrm{m}^{2}$ ). About $5 \%$ of the total number of synapses in neuropil of RA contained perforated PSDs at all ages studied ( $28 \mathrm{~d}, 5.0 \%$; $53 \mathrm{~d}, 4.0 \%$; adult, $5.8 \%$ ).

\section{Developmental changes in afferents from $H V C$ and IMAN: lesioned birds}

Density of degenerating synapses. Between day 25 and adulthood, there was significant rearrangement of afferents from $\mathrm{HVc}$ and IMAN in neuropil of RA. A two-way ANOVA yielded a significant interaction between the factors of age and treatment $[F(4,43)=5.08 ; p<0.002]$. The density of degenerating synapses from $\mathrm{HVc}$ increased significantly between days 25 and 53 $[F(1,43)=4.70 ; p<0.04)$, but did not change significantly thereafter (Figs. 3, 4). The synapses from IMAN showed exactly the opposite trend. The density of IMAN synapses decreased $80 \%$ between days 25 and $53[F(1,43)=8.66 ; p<0.006]$, but did not change significantly between day 53 and adulthood. Lesion of either HVc or lMAN significantly increased the density of degenerating synapses at all ages tested. At day 25 , there was a significantly greater density of synapses from IMAN than from HVc, but this difference was not significant at the other ages.

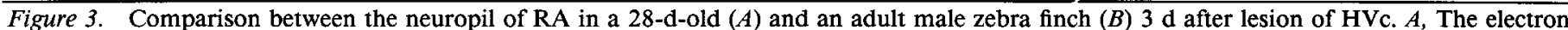

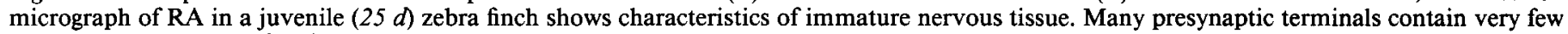

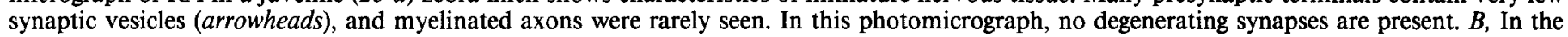

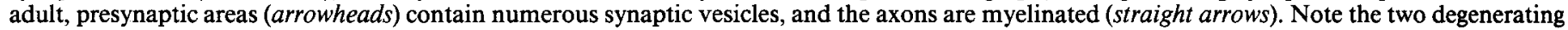
synapses (curved arrows). Magnification, 21,000×. 

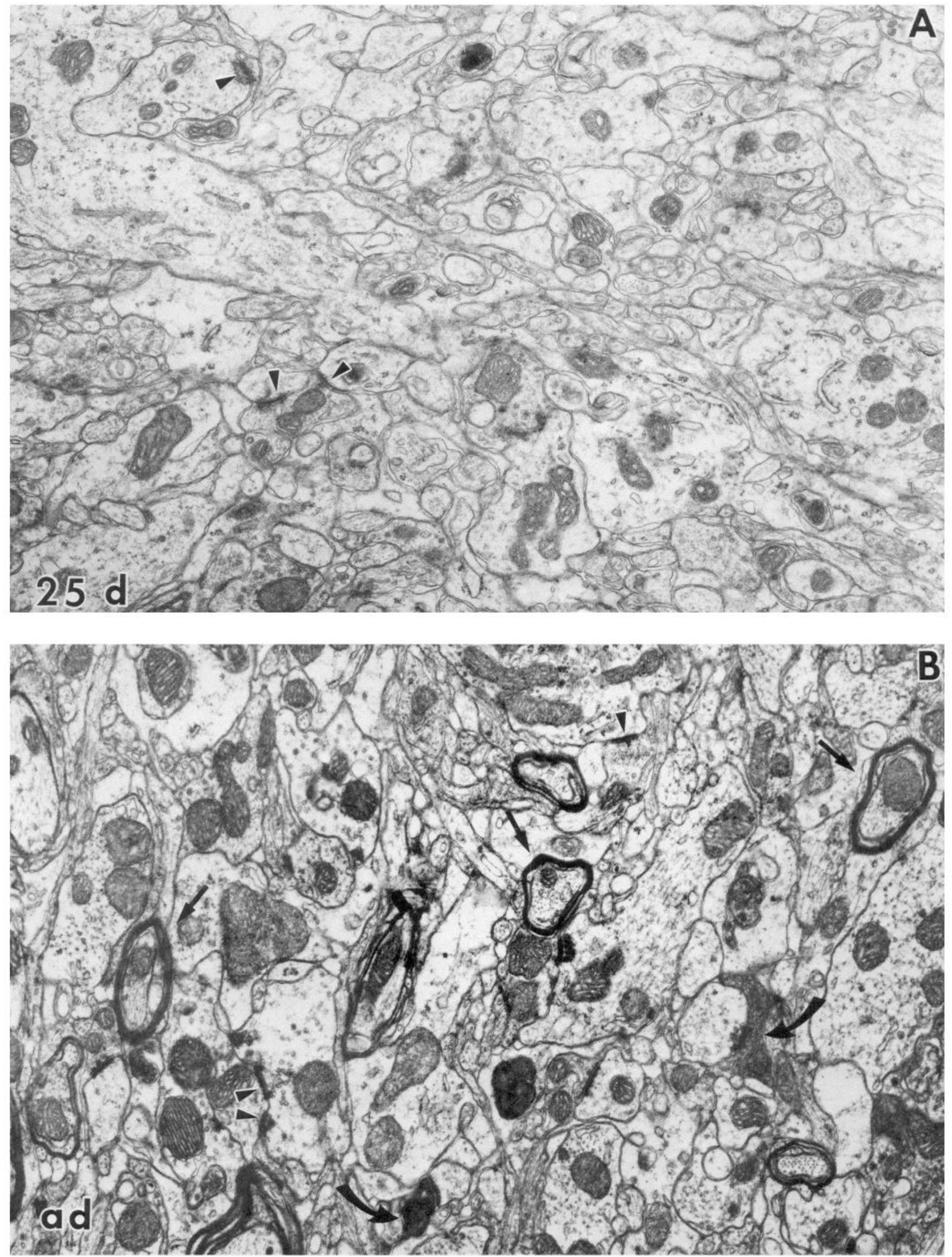


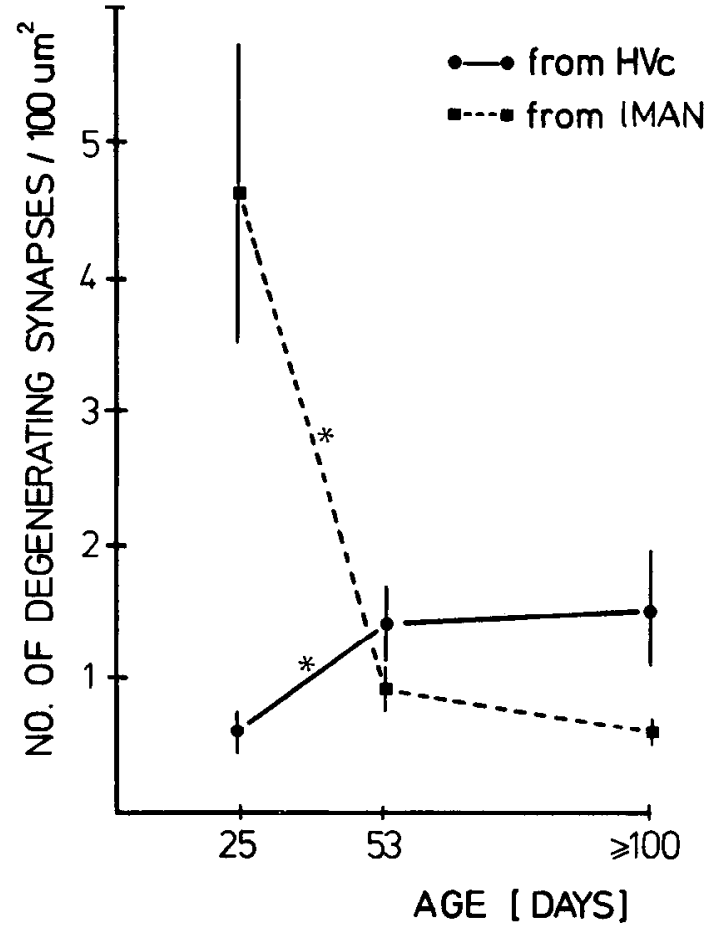

Figure 4. Density (synapses per $100 \mu \mathrm{m}^{2}$ ) of degenerating synapses in the neuropil of RA after a lesion of HVc or IMAN (mean \pm SEM). Between day 25 and adulthood, there was a significant rearrangement of afferents from HVc and IMAN in RA. The density of degenerating synapses from HVc increased between days 25 and 53 and did not change thereafter. The density of degenerating synapses from IMAN showed the opposite trend; they decreased significantly between day 25 and adulthood, and the majority of this change occurred between days 25 and $53 .^{*}, p<0.05$.

The changes in density of degenerating synapses on shafts showed the same patterns of change as did all synapses. There was a significant interaction of treatment and age $[F(4,43)=$ $6.56, p<0.0003]$. There was a significant decline in the density of shaft synapses from IMAN between days 25 and $53[F(1,43)$ $=20.5 ; p<0.0001]$, and no significant change thereafter (day $25,1.5 \pm 0.36$; day $53,0.40 \pm 0.10$; adult, $0.30 \pm 0.11$ ). Although the density of $\mathrm{HVc}$ shaft synapses tended to increase with age (day $25,0.26 \pm 0.05$; day $53,0.50 \pm 0.12$; adult, 0.56 \pm 0.15 ), these changes were not statistically significant.

The density of degenerating synapses on dendritic spines also changed in a similar manner. There was a significant interaction between age and type of lesion $[F(2,35)=16.3 ; p<0.0001]$. The density of degenerating spine synapses from $\mathrm{HVc}$ increased with age (day $25,0.33 \pm 0.09$; day $53,0.85 \pm 0.17$; adult, 0.94 \pm 0.29 ). The changes between days 25 and 53 were significant $[F(1,35)=7.5 ; p<0.01]$, but the change thereafter was not. In contrast, the density of spine synapses from IMAN declined significantly between days 25 and $53[F(1,35)=16.5 ; p=0.0003]$, but not thereafter (day 25, $3.1 \pm 0.82$; day 53, $0.49 \pm 0.11$; adult, $0.35 \pm 0.07$ ). The density of degenerating spine synapses from IMAN differed significantly from the density from HVc at day 28 and in adulthood.

Total number of degenerating synapses. In the two-way ANOVA comparing the total numbers of degenerating synapses, there was a significant interaction between the effects of age and type of lesion $[F(4,43)=7.62 ; p<0.0001]$. At day 25 , the number

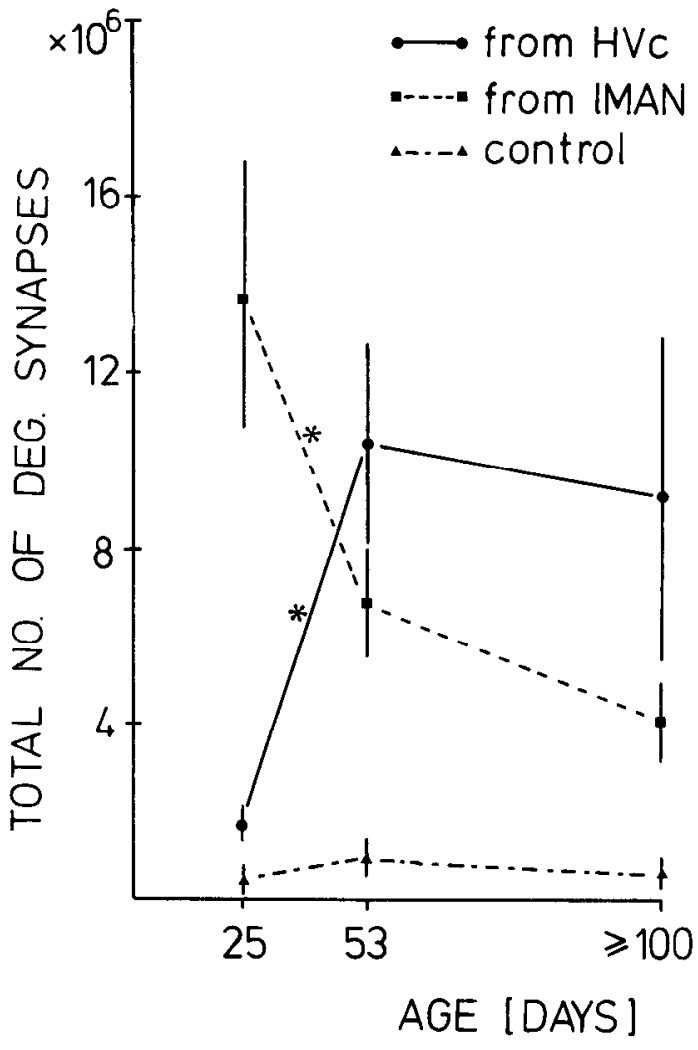

Figure 5. Total number of degenerating synapses (mean \pm SEM) in RA neuropil after a lesion of HVc or IMAN. The number of synapses in RA originating from $\mathrm{HVc}$ increased sixfold between days 25 and 53 . During the same period, IMAN retracted $50 \%$ of its synaptic contacts. After day 53, no significant changes occurred in the number of degenerating synapses. The incidence of degenerating synapses in control animals was low at all ages studied. ${ }^{*}, p<0.05$

of synapses originating from $\mathrm{HVc}$ was low and was not significantly different from the number that occurrcd in unlesioned control birds (Fig. 5). At this age, however, IMAN made many more synapses than $\mathrm{HVc}[F(1,43)=25.9 ; p<0.0001]$. Between days 25 and 53 , the number of synapses from $\mathrm{HVc}$ increased sixfold $[F(1,43)=17.5 ; p=0.0001]$, after which there was no significant change into adulthood. In IMAN, the total number of synapses decreased between days 25 and $53[F(1,43)=5.29$; $p<0.03$ ), after which there was no significant change. Thus, though there were eight times more synapses from IMAN than from $\mathrm{HVc}$ in the neuropil of RA of 25-d-old zebra finches, by adulthood there were 2.4 times as many synapses from $\mathrm{HVc}$ as from IMAN (not significant).

The same trends can be seen when the total number of degenerating synapses are categorized into spine and shaft synapses (Fig. 6). For both shaft and spine synapses, there was a significant interaction between the effects of age and type of lesion [for shafts: $F(4,43)=4.34, p<0.005$; for spines: $F(2,35)=15.0, p$ $<0.0001]$. The number of degenerating synapses from $\mathrm{HVc}$ on shafts or spines increased dramatically between days 25 and 53 [for shafts: $F(1,43)=10.6, p<0.003$; for spines: $F(1,35)=$ $15.9, p=0.0003$ ] and stayed constant thereafter. At day 25 there was no statistically significant difference between controls and $\mathrm{HVc}$-lesioned animals in the numbers of degenerating shaft synapses, though there were significant differences at the other two ages. In IMAN, shaft and spine synapses decreased between 

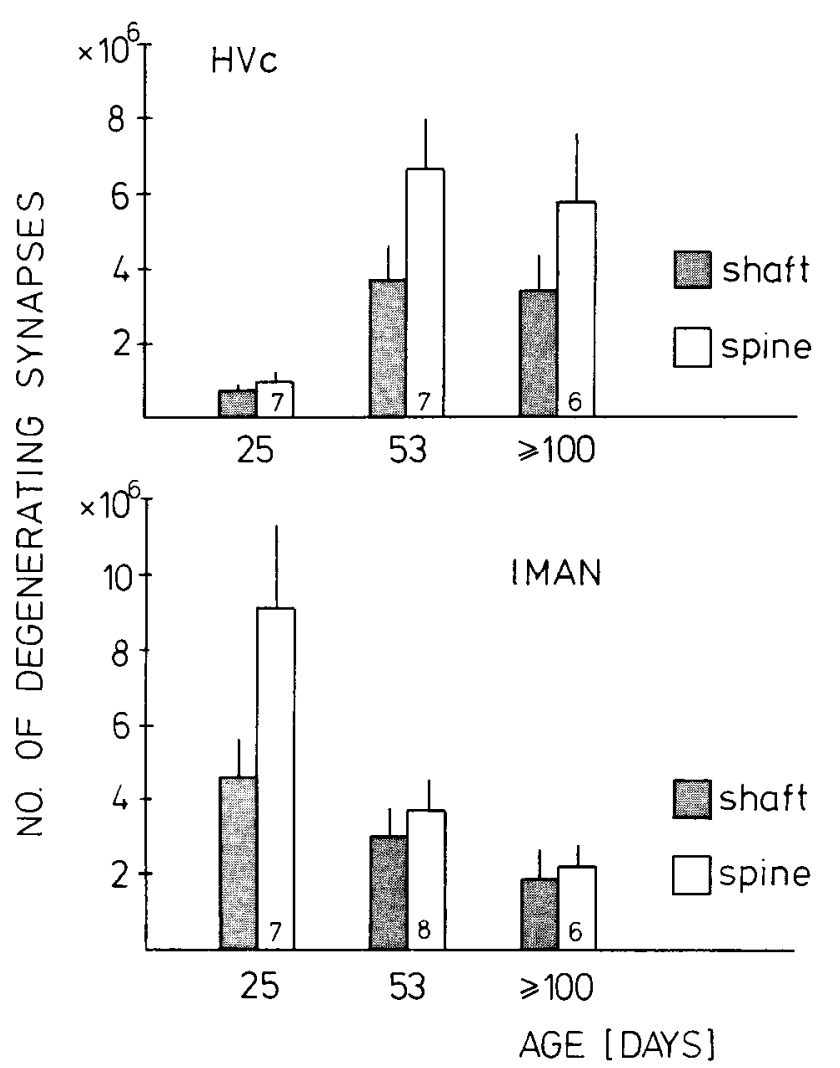

Figure 6. Total number of degenerating synapses (mean \pm SEM) in RA neuropil after lesion of HVc or IMAN on dendritic shafts and spines. HVc and IMAN made synaptic contacts with both dendritic shafts and spines in the neuropil of RA. The ratio of shaft-to-spine synapses from HVc was about $1: 2$, except at day 25 , when HVc made about the same number of contacts on shafts and spines. The ratio of shaft-to-spine synapses from IMAN was about 1:2 at day 25 , whereas at later ages the ratio was roughly $1: 1$. The numbers in the open columns indicate the number of animals.

days 25 and 53 [not significant for shafts; for spines: $F(1,35)=$ $6.75, p<0.02]$ and remained stable thereafter.

Size of synapses. There was a significant main effect of type of lesion on the size of degenerating synapses found in the neuropil of $\mathrm{RA}[F(1,35)=9.39 ; p<0.004]$, which reflected the fact that synapses from IMAN were significantly larger than those from $\mathrm{HVc}$ at day $53[F(1,35)=4.53 ; p<0.04]$ and in adulthood $[F(1,35)=6.95 ; p<0.02]$. There was no significant main effect of age, nor a significant interaction for this measure (Figs. 7-9).

\section{Discussion}

The aim of the present study was to measure developmental changes in synaptic input to the neuropil in RA, a nucleus thought to be pivotal in the motor control of song because of its role as conduit for all tclencephalic control of the syringeal muscles (Nottebohm et al., 1976). Our results indicate that there are major changes in the number of synapses between days 25 and 53. The total number of synapses tripled in this period (Fig. 2) as a result of increases in synapses from $\mathrm{HVc}$, and in synapses from unknown origin, probably from other RA neurons. In contrast, the number of synapses from IMAN declined twofold at this same time. This developmental organization of synaptic contacts in RA occurs at a time when the young male is forming

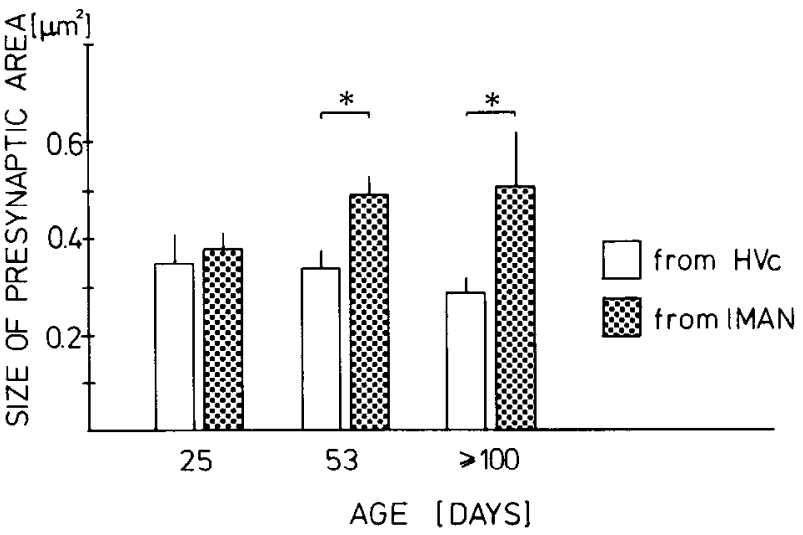

Figure 7. The size of degenerating presynaptic profiles in RA after a lesion of HVc or IMAN (mean \pm SEM). The size of the profiles from $\mathrm{HVc}$ did not change with age. The modest increase $(30 \%)$ in the sizc of profiles originating in IMAN was not statistically significant. However, synapses from IMAN were significantly larger than those from $\mathrm{HVc}$ at day 53 and in adulthood. ${ }^{*}, p<0.05$.

acoustic memories of songs that he has heard and is matching his own vocalizations to songs that he has adopted as models. It is likely that these synaptic changes in RA play a significant role in these learned changes in song behavior.

\section{Anatomical development of $R A$}

At day 25, RA is immature in its overall volume, volume of its neuropil, and neuron size (Bottjer et al., 1985, 1986; Konishi and Akutagawa, 1985; Herrmann and Bischof, 1986; E. Nordeen and K. Nordeen, 1988). Our observation of dendritic growth cones at this age adds to this picture, because such growth cones are commonly believed to be found primarily in undifferentiated neuronal circuits (e.g., Tanaka and Alexander, 1978; Williams et al., 1986; Bunso-Bechtold and Vinsant, 1988). In contrast, synaptic density already reached adult levels in 25-d-old birds (see also Clower and DeVoogd, 1988). Because of the tremendous increase of the RA volume, however, the total number of synapses in the neuropil of RA increased between days 25 and 53, from about 40 million to about 110 million. After day 53, there was a small decline (14\%) in the total number of synapses. A similar developmental overproduction and subsequent elimination of synapses has been observed in many neuronal systems (Cragg, 1975; Purves and Lichtman, 1980; O’Kusky, 1985; Holstein et al., 1985; Rakic et al., 1986). The length of the PSD increased significantly between days 25 and 53 .

We were surprised to find that the incidence of degenerating synapses in RA from unlesioned birds did not change across the ages we examined. We had expected a large proportion of degenerating profiles at day 25 in our control birds because a high incidence of pyknotic cells has been reported in RA at this age (Kirn and DeVoogd, 1989). The constancy of degenerating synapses in unlesioned birds may be explained if it assumed that the degenerating synapses were removed so quickly that we would not detect them with the present methods.

\section{Anatomical development of $H V c$ and $I M A N$}

HVc and IMAN, the only known afferent nuclei to RA (Bottjer et al., 1989), have opposite developmental patterns between days 25 and 53 (Bottjer et al., 1985, 1986). The volume of IMAN decreases between days 25 and 53 because of a $50 \%$ decline in the number of neurons within this nucleus (Bottjer et al., 1985; 

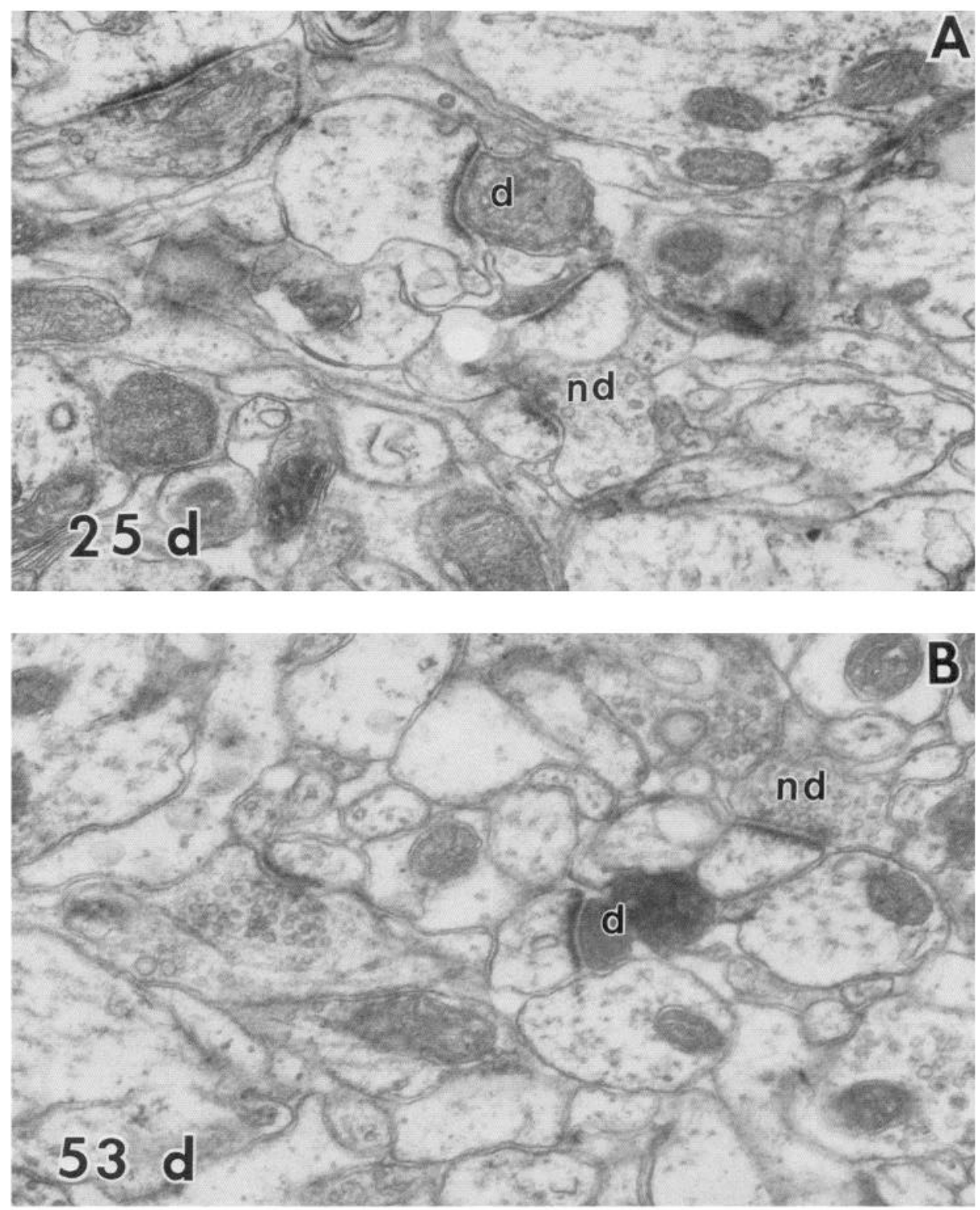

Figure 8. Degenerating synapses in nucleus RA $3 \mathrm{~d}$ after a lesion of $\mathrm{HVc}$ at day $25(A)$, day $53(B)$, and in adulthood $(C)$. In $A$, a degenerating synaptic profile $(d)$ makes contact with a dendritic shaft. A nondegenerating profile (nd) is also indicated. In $B$, a degenerating synapse $(d)$ makes contact with a dendritic spine. In $C$, there is a degenerating axospinous synapse $(d)$, resulting from a lesion of $\mathrm{HVc}$, and a nondegenerating synapse ( $n d$ ) on a dendritic spine. Magnification, $36,000 \times$.

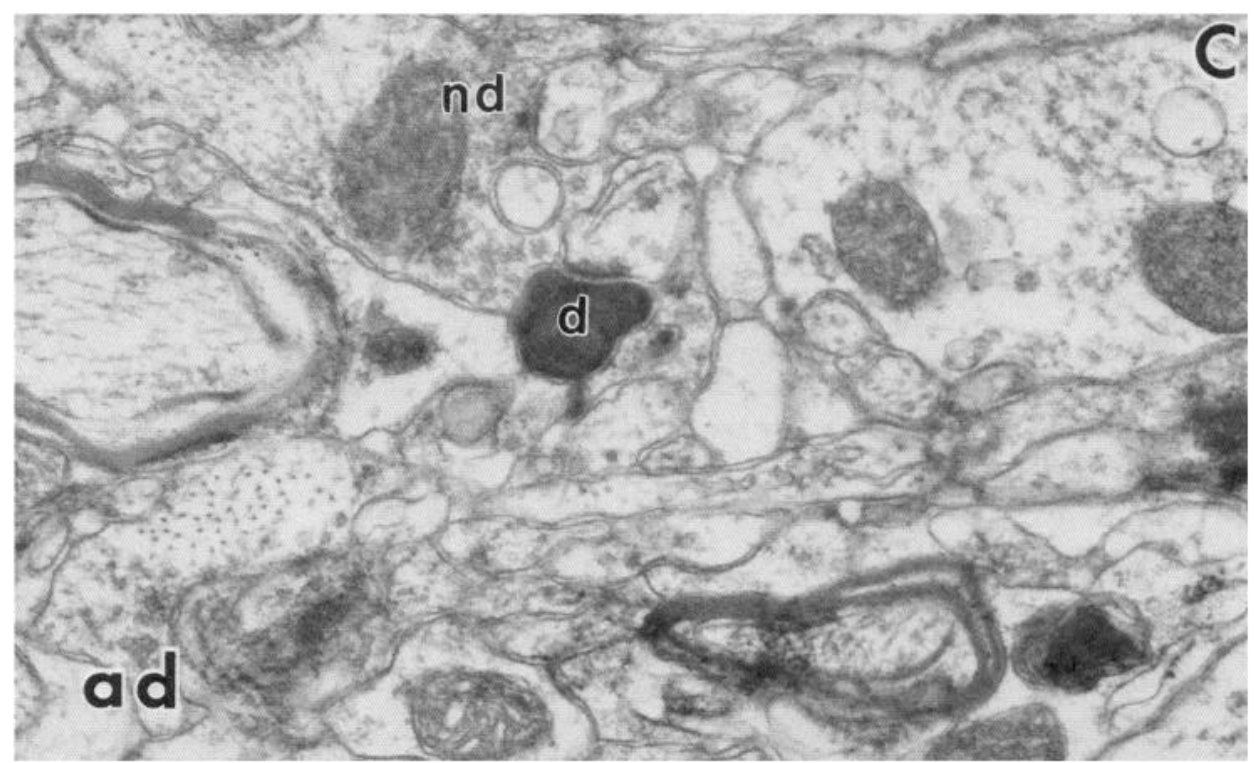



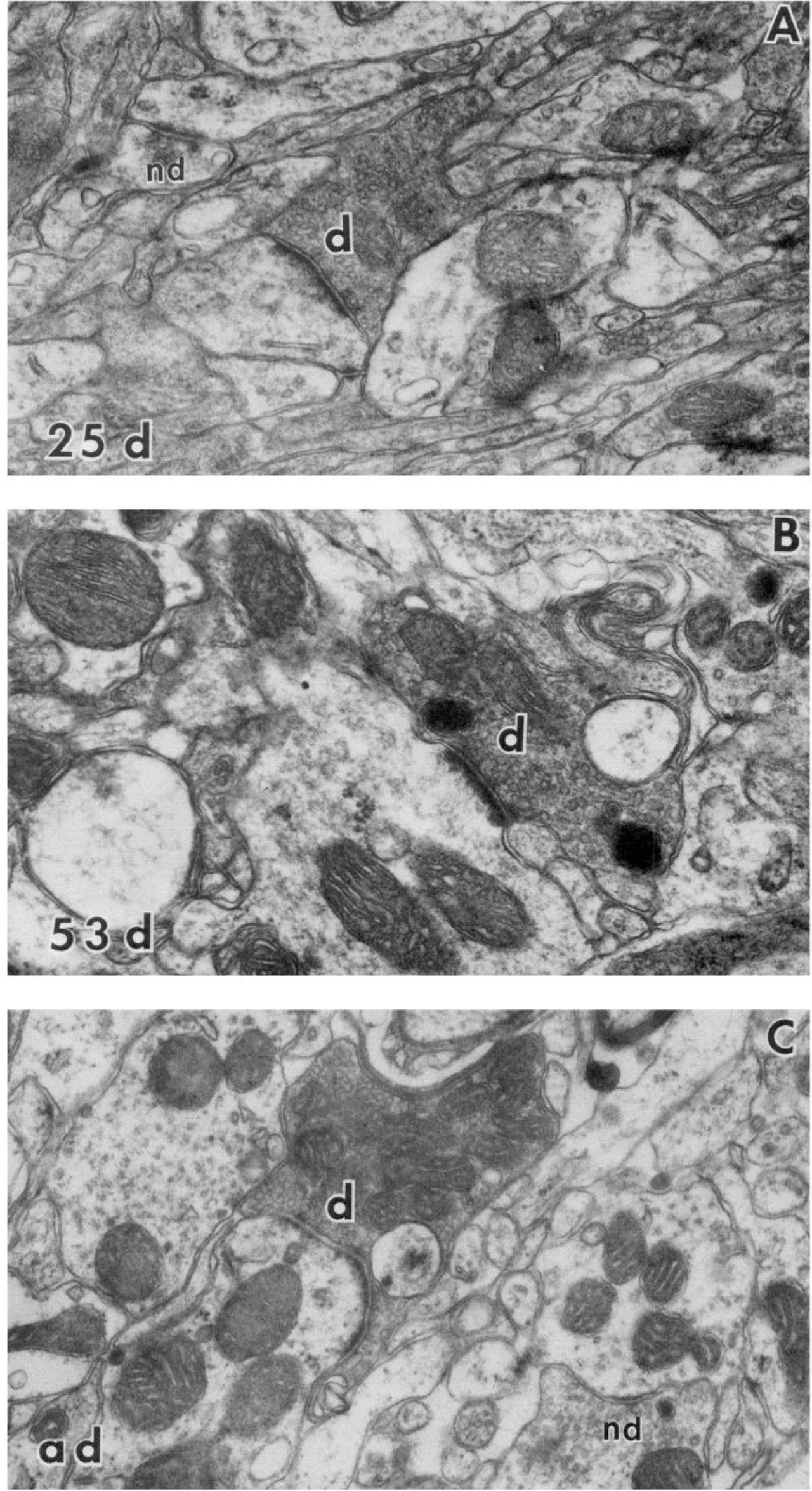

Figure 9. Degenerating synapses in the neuropil of RA 4-5 d after a lesion of IMAN at day $25(A)$, day $53(B)$, and in adulthood $(C)$. In $A$, a degenerating presynaptic terminal (d) contains numerous vesicles and is much larger in size than nondegenerating terminals (nd). In $B$, the dark, degenerating terminal $(d)$ engulfs a small, light profile, probably a spine. In $C$, there is a large degenerating shaft synapse that engulfs a small, nondegenerating profile. A nondegenerating shaft synapse $(n d)$ is also marked. Presynaptic terminals originating from IMAN were much larger than those from HVc (cf. Fig. 8). Magnification, 36,000 $\times$. 
Figure 10. Schematic cartoon of the development of the synaptic composition of RA neuropil. Each symbol represents 2 million synapses. At day 25 , $37 \%$ of the synapses in RA are of IMAN origin, whereas only about $5 \%$ stem from $\mathrm{HVc}$. About $60 \%$ are presumably intrinsic synapses, because they were not labelled by either $\mathrm{HVc}$ or IMAN lesions. The RA of 53-d-old birds is composed of $9 \%$ synapses from $\mathrm{HVc}$ and $6 \%$ from IMAN, which leaves $85 \%$ for intrinsic synapses. In adult zebra finches, only about $4 \%$ of the RA synapses stem from IMAN, whereas $10 \%$ are of HVc origin.
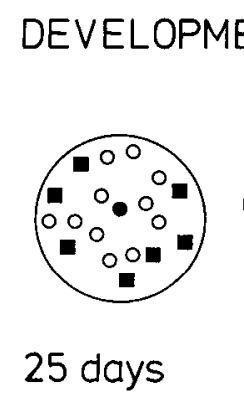

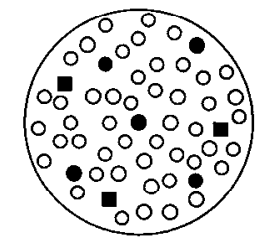

53 days

\section{SYNAPTIC COMPOSITION OF RA}

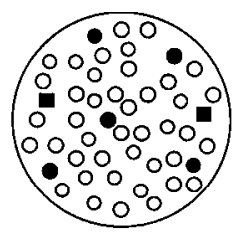

adult
- HVc afferents

- IMAN afferents

- intrinsic synapses
Bottjer and Sengelaub, 1989). At the same time, HVc grows dramatically, increasing in volume, in number and size of neurons, and in the incidence of androgen-accumulating cells (Bottjer et al., 1986; Herrmann and Bischof, 1986; Nordeen et al., 1987; E. Nordeen and K. Nordeen, 1988; K. Nordeen and E. Nordeen, 1988), and axons from HVc are thought to grow into RA (Konishi and Akutagawa, 1985). Our data indicate that the concomitant growth of $\mathrm{HVc}$ and atrophy of IMAN are reflected in dramatic changes in synaptic input from these nuclei to the neuropil of RA. At day 25, IMAN sends about 14 million synapses to the neuropil of RA, about $37 \%$ of the total number. This number drops to about 7 million synapses at day $53,6 \%$ of the total. Conversely, $\mathrm{HVc}$ gives rise to 1.7 million synapses to RA neuropil at day 25 (5\% of the total), which increases to about 10 million by day 53 ( $9 \%$ of the total; Fig. 10$)$.

One can use published estimates of the numbers of neurons in RA to derive estimates of the numbers of synapses made on the dendrites of individual RA neurons at various ages. There are 14,500 neurons in each hemisphere at day $25,13,043$ at day 53 (Bottjer et al., 1986), and 13,600 in adults (Konishi and Akutagawa, 1985).Thus, the dendrites of a single RA neuron receive on average about 120 synapses from HVc at day 25 . This number increases to about $650-800$ synapses by day 53 and stays stable thereafter. On the other hand, the dendrites of a single RA neuron are innervated by about 950 synapses from IMAN at day 25 , but only by about half this number (520) by day 53. The dendrites of each RA neuron in adult zebra finches receive only about 300 synapses from $1 \mathrm{MAN}$.

It is also possible to calculate the number of afferent synapses that individual IMAN neurons send to the ncuropil of RA, using our data from synapse numbers and published data for numbers of neurons at various stages of development. At day 25, there are about 16,000-19,800 1MAN neurons (Bottjer et al., 1985; Bottjer and Sengelaub, 1989), of which 54\% project to RA (Korsia and Bottjer, 1990). Our present data show that, at day 25, IMAN makes 13.7 million synaptic contacts in RA, indicating that individual IMAN neurons make about 1,400 synaptic contacts in neuropil of RA. By day 53, there are about 9600 neurons in IMAN (Bottjer et al., 1985), about 5200 of which project to RA and make a total of 6.8 million synaptic contacts, so that the average IMAN neuron makes about 1300 synaptic contacts in neuropil of RA. Although there are no published reports of the number of neurons in adult IMAN, if one assumes a stable neuronal population after day 53 and a stable percentage of projection neurons (Korsia and Bottjer, 1990), the number of synaptic contacts per IMAN neuron in RA is further reduced to 780 in adulthood. Even the higher IMAN neuron counts of
E. Nordeen and K. Nordeen (1988; 32,750 and 12,250 at days 20 and 53, respectively) lead to the same conclusion, that individual IMAN neurons lose about half of their synaptic contacts in RA between day 25 and adulthood. Unfortunately, there are no comparable, consistent data sets on the number of neurons and the percentage of projection neurons in $\mathrm{HVc}$ (cf. Bottjer et al., 1986; E. Nordeen and K. Nordeen, 1988).

Because IMAN and HVc have a common target (RA), their opposite patterns of development lead to the hypothesis that the regression of IMAN and growth of $\mathrm{HVc}$ are causally related. On the one hand, HVc axons growing into RA may displace IMAN synapses and lead to the death of IMAN neurons. Alternatively, the loss of IMAN synaptic contacts in HVc may allow ingrowth of HVc axons. Our data support the temporal correlation of the loss of IMAN synapses and increase in HVC synapses, both of which occurred between days 25 and 53 . However, these nuclei account for only a minority of the synapses in RA neuropil. The other synapses probably stem from RA neurons themselves. It seems unlikely that the regression of IMAN is caused by competition of HVc axons invading RA, because the $\mathrm{HVc}$ axons never contribute a large proportion of the synapses in RA. Thus, there may never be strong competition between the synapses from these two nuclei. Of course, if the synapses from IMAN and HVc compete for a subset of synaptic space in RA, then IMAN-HVc synaptic competition may be more fierce.

\section{Comparison between $H V_{C}$ and IMAN synapses in the neuropil of $R A$}

One of our main findings is that, in RA neuropil of adult zebra finches, synapses from $\mathrm{HVc}$ were much more numerous than those from IMAN. One class of neuron in canary RA, the hormone-sensitive type IV neuron, receives 20 times more synapses from HVc than from IMAN (Canady et al., 1988). If this ratio is the same in zebra finches, it can be concluded that the other neuron types in zebra finch $R A$ receive a much higher percentage of IMAN inputs, because the ratio of IMAN to HVc synapses is about 1:2 in adult zebra finches. However, as stated above, during early development the picture is reversed. In 25-d-old zebra finches, about $37 \%$ of the synapses in neuropil of RA are of IMAN origin, whereas only about $5 \%$ come from HVc. After this age, IMAN retracts about $70 \%$ of its synaptic contacts in the neuropil of RA, both spine and shaft synapses. The loss of synapses reflects both a loss in total neuron number and an actual loss of synapses per neuron.

Ontogenetic changes in size of synapses from $1 \mathrm{MAN}$ and $\mathrm{HVc}$ may contribute to the functional relationship of these regions 
to RA. Synapses from IMAN and HVc had about the same terminal size at day 25 , after which terminals from $\mathrm{HVc}$ remained constant or declined slightly, but those from IMAN grew until they were about twice the size of $\mathrm{HVc}$ terminals in adults. The growth of IMAN synapses during the time of profound loss in the number of terminals contrasts with the addition of more $\mathrm{HVc}$ terminals of constant size. It is conceivable that the developmental increase in the size of terminals from IMAN axons partly offsets the loss in terminal number, so that the ability of IMAN neurons to drive RA neurons may not be reduced as much as would be predicted from the data on terminal number alone.

The typc of HVc and IMAN synapses also appcarcd to change during development. IMAN terminals were often packed with synaptic vesicles, even at day 25 , when many synapses in RA looked immature. They had few synaptic vesicles and these were often not closely attached to the presynaptic membrane. At all ages, degenerating synapses from IMAN (but not from HVc) often were found to engulf small dendritic spines. Canady et al. (1988) mentioned a high frequency of degenerating IMAN terminals on Y-shaped spines. Our sampling method did not allow detection of this synaptic type, but it is possible that it corresponds to the engulfed spine seen in our material. Interestingly, in adulthood $5 \%$ of the synapses originating from $\mathrm{HVc}$ had perforated PSDs, whereas perforations were rarely found in synapses from IMAN, at any age. In general, perforated PSDs are thought to be involved in synapse turnover or synapse splitting (Nieto-Sampedro et al., 1982; Carlin and Siekevitz, 1983; Dyson and Joncs, 1984; Gcinisman et al., 1987). If this interpretation is valid, then $\mathrm{HVc}$ synapses express a higher degree of plasticity than IMAN synapses.

\section{Implications for song learning}

As mentioned earlier, song learning is a process that involves two steps, sensory and sensory-motor learning. The period of sensory learning begins perhaps as early as day 20 and ends by days 35-50 (Böhner, 1983; Eales, 1985, 1987). Sensory-motor learning begins around day 25 , proceeds most rapidly until day 60 , but may not end completely until day 90 (Immelmann, 1969; Eales, 1985, 1987; Böhner, 1987). During these learning periods, a number of neuronal events take place that may explain the dramatic alterations in behavior. There is an increase in volume of $\mathrm{HVc}, \mathrm{RA}$, and area $\mathrm{X}$; an increase in neuron number in $\mathrm{HVc}$ and area $X$; an increase in neuron size in RA; and a decrease in neuron number in IMAN (Bottjer et al., 1985, 1986; Konishi and Akutagawa, 1985; Herrmann and Bischof, 1986; Bottjer and Sengelaub, 1989). At the same time, HVc develops a strong projection to RA (Konishi and Akutagawa 1985; K. Nordeen and E. Nordeen, 1988; Mooney and Konishi, 1989). Lesions of IMAN between days 25 and 60 have profound effects on the zebra finch's ability to produce song later in life (Bottjer et al., 1984), whereas ablations of this nucleus in adult birds have little effect on singing behavior (Bottjer et al., 1984). The present data strengthen these behavioral and anatomical data by adding evidence for synaptic growth and addition in the HVc-to-RA pathway and for large-scale loss of synapses in RA from IMAN. IMAN loses about $70 \%$ of its synaptic connections to the neuropil of RA between day 25 and adulthood, mostly between days 25 and 53, at the time when lesions of IMAN produce the most pronounced effects on song learning. It is unlikely that the IMAN-to-RA projection is completely without function in adults, as might be inferred from the effects of IMAN lesions on behavior, because lMAN makes 4 million synapses in the neuropil of RA in adult zebra finches. The growth of synapses from IMAN between day 25 and adulthood also supports the ided that they serve a specific, unknown function. The observation that $\mathrm{HVC}$ synapses arrive in RA at the time when the young zebra finch actually produces song for the first time in his life, strengthens the idea that the HVc-RA-nXIIts projection is directly involved in the motor control of singing. Because of the dramatic increase in the number of synapses from $\mathrm{HVc}$ in RA after day 25, there remains the important question of how the acoustic environment influences the pattern of connections made by these new synapscs during the process of song learning.

\section{References}

Arnold AP (1975) The effects of castration on song development in zebra finches (Poephila guttata). J Exp Zool 191:261-277.

Arnold AP (1991) Developmental plasticity in neural circuits controlling bird song: sexual differentiation and the neural basis of learning. In: Developmental neuroethology (Stehouwer DJ, ed), in press. New York: Wiley.

Blackstad TW (1965) Mapping of experimental axon degeneration by electron microscopy of Golgi preparations. Z Zellforsch 67:819-834.

Böhner J (1983) Song learning in the zebra finch (Taeniopygia guttata): selectivity in the choice of a tutor and accuracy of song copies. Anim Behav 31:231-237.

Böhner J (1987) Der Gesangserwerb Beim Australischen Zebrafinken (Taeniopygia guttata castanotis). PhD thesis, University of Bielefeld, Germany.

Bottjer SW, Sengelaub DR (1989) Cell death during development of a forebrain nucleus involved with vocal learning in zebra finches. $J$ Neurobiol 20:609-618.

Bottjer SW, Miesner EA, Arnold AP (1984) Forebrain lesions disrupt development but not maintenance of song in passerine birds. Science 224:901-903.

Bottjer SW, Glaessner SL, Arnold AP (1985) Ontogeny of brain nuclei controlling song learning and behavior in zebra finches. J Neurosci 5:1556-1562.

Bottjer SW, Miesner EA, Arnold AP (1986) Changes in neuronal number, density and size account for increases in volume of song-control nuclei during song development in zebra finches. Neurosci Lett 67: 263-268.

Bottjer SW, Halsema KA, Brown SA, Miesner EA (1989) Axonal connections of a forebrain nucleus involved with vocal learning in zebra finches. J Comp Neurol 279:312-326.

Bunso-Bechtold JK, Vinsant SL (1988) Distribution of growth cones and synapses in developing laminar and interlaminar regions of the dorsal lateral geniculate nucleus. J Neurosci 8:2677-2692.

Canady RA, Burd GD, DeVoogd TJ, Nottebohm F (1988) Effects of testosterone on input received by an identified neuron type of the canary song system: a Golgi/electron microscopy/degeneration study. J Neurosci 8:3770-3784.

Carlin RK, Siekevitz P (1983) Plasticity in the central nervous system: do synapses divide? Proc Natl Acad Sci USA 80:3517-3521.

Clower RP, DeVoogd TJ (1988) Ultrastructural correlates of song development in the zebra finch. Soc Neurosci Abstr 14:285.

Colonier M, Beaulieu C (1985) An empirical assessment of stereological formulae applied to the counting of synaptic disks in the cerebral cortex. J Comp Neurol 231:175-179.

Cragg B (1975) The development of synapses in the visual system of the cat. J Comp Neurol 160:147-166.

DeHoff RT, Rhines FN (1961) Determination of number of particles per unit volume from measurements made on random plane sections: the general cylinder and the ellipsoid. Trans AIME 221:975-982.

Dyson SE, Jones DG (1984) Synaptic remodelling during development and maturation: junction differentiation and splitting as a mechanism for modifying connectivity. Dev Brain Res 13:125-137.

Fales LA (1985) Song learning in rebra finches: some effects of song model availability on what is learnt and when. Anim Behav 33:12931300.

Ealcs LA (1987) Song lcarning in female-raised zebra finches: another look at the sensitive phase. Anim Behav 35:1356-1365. 
Geinisman Y, Morrell F, de Toledo-Morrell L (1987) Axospinous synapses with segmented postsynaptic densities: a morphologically distinct synaptic subtype contributing to the number of profiles of "perforated' synapses visualized in random sections. Brain Res 423:179188.

Herrmann K, Bischof H-J (1986) Delayed development of song control nuclei in the zebra finch is related to behavioral development. $J$ Comp Neurol 245:167-175.

Holstein GR, Pasik T, Pasik P, Hamori J (1985) Early postnatal development of the monkey visual system. II. Elimination of retinogeniculate synapses. Dev Brain Res 20:15-31.

Ichikawa M, Arissian K, Asanuma H (1985) Distribution of corticocortical and thalamocortical synapses on identified motor cortical neurons in the cat: Golgi, electron microscopic and degeneration study. Brain Res 345:87-101.

Immelmann K (1969) Song development in the zebra finch and other estrildid finches. In: Bird vocalizations (Hinde RE, ed), pp 61-74. Cambridge: Cambridge UP.

Kirn JR, DeVoogd TJ (1989) Genesis and death of vocal control neurons during sexual differentiation in the zebra finch. $J$ Neurosci 9:3176-3187.

Konishi M, Akutagawa E (1985) Neuronal growth, atrophy, and death in a sexually dimorphic song nucleus in zebra finches. Nature 315: 145-147.

Korsia S, Bottjer SW (1990) Developmental changes in the cellular composition of a brain nucleus involved with song learning in zebra finches. Neuron 3:451-460.

Matsumoto A, Arai Y (1981) Effects of androgen on sexual differentiation of synaptic organization in the hypothalamic arcuate nucleus: an ontogenetic study. Neuroendocrinology 33:166-169.

Mooney R, Konishi M (1989) NMDA receptors mediate synaptic transmission in a zebra finch song control nucleus. Soc Neurosci Abstr 15:347.

Moriiumi T, Nakamura Y, Kitao Y, Kudo M (1987) Ultrastructural analyses of afferent terminals in the subthalamic nucleus of the cat with a combined degeneration and horseradish peroxidase tracing method. J Comp Neurol 265:159-174.

Mugnani E, Friederich VL Jr (1982) Electron microscopy: identifi- cation and study of normal and degenerating neural elements by electron microscopy. In: Neuroanatomical tract-tracing methods (Heimer L, RoBards MJ, eds), pp 377-406. New York: Plenum.

Nieto-Sampedro M, Hoff SF, Cotman CW (1982) Perforated postsynaptic densities: probable intermediates in the synapse turnover. Proc Natl Acad Sci USA 79:5718-5722.

Nordeen EJ, Nordeen KW (1988) Sex and regional differences in the incorporation of neurons born during song learning in zebra finches. J Neurosci 8:2869-2874.

Nordeen EJ, Nordeen KW, Arnold AP (1987) Sexual differentiation of androgen accumulation in the zebra finch brain through selective cell loss and addition. J Comp Neurol 259:393-399.

Nordeen KW, Nordeen EJ (1988) Projection neurons within a vocal motor pathway are born during song learning in zebra finches. Nature 334:149-151.

Nottebohm F, Stokes TM, Leonard CM (1976) Central control of song in the canary (Serinus canarius). J Comp Neurol 165:457-486.

O'Kusky JR (1985) Synapse elimination in developing visual cortex: a morphometric analysis in normal and dark-reared cats. Dev Brain Res 22:81-91.

Purves D, Lichtman JW (1980) Elimination of synapses in the developing nervous system. Science 210:153-157.

Rakic P, Bourgeois J-P, Eckenhoff MF, Zecevic N, Goldman-Rakic PS (1986) Concurrent overproduction of synapses in diverse regions of the primate cerebral cortex. Science 232:232-235.

Schwarcz R, Hokfelt T, Fuxe K, Jonsson G, Goldstein M, Terenius L (1979) Ibotenic acid-induced neuronal degeneration: a morphological and neurochemical study. Exp Brain Res 37:199-216.

Tanaka D, Alexander B (1978) Golgi and electron microscopic evidence for growth cones in the caudate nucleus of the neonatal dog. Exp Neurol 60:614-623.

Williams RW, Bastiani MJ, Lia B, Chalupa LM (1986) Growth cones, dying axons, and development fluctuations in the fiber population of the cat's optic nerve. J Comp Neurol 246:32-69.

Woodward JA, Bonett EG, Brecht ML (1990) Introduction to linear models and experimental design. San Diego: Harcourt, Brace, Jovanovich. 